\title{
Knowledge and awareness about fertility preservation among female patients with cancer : a cross-sectional study
}

\author{
Reeta Mahey, MD, DNB, Shobha Kandpal, MSS, Monica Gupta, MD, DNB, MRCOG, \\ Perumal Vanamail, PhD Biostatistics, Neerja Bhatla, MD, FICOG, Neena Malhotra, MD, DNB, FRCOG \\ Department of Obstetrics \& Gynecology, All India Institute of Medical Sciences, New Delhi, India
}

\section{Objective}

The incidence of women in the reproductive age group diagnosed with cancer has recently increased. However, very few patients opt for or are offered fertility preservation (FP) strategies because of a significant lack in awareness. The present study was conducted to evaluate the knowledge of the effect of cancer treatment on fertility and available options for FP.

\section{Methods}

This was a cross-sectional study conducted at a tertiary care center from March 2019 through August 2019. One hundred female patients with gynecological or nongynecological cancer and 18-40 years of age were interviewed. The participants were categorized on the basis of the modified Kuppuswamy socioeconomic status (SES) scale and the responses of the patients in the different categories were compared.

\section{Results}

More than half the patients (63\%) were in the 20-35-year age group. Most of the patients $(71 \%)$ were married, and of them, $28(39.4 \%)$ desired to have children. Only $32 \%$ of the patients were aware of the detrimental effect of cancer and its treatment on future fertility, and of them, only $28 \%$ could specify the gonadotoxic effect of chemotherapy. Knowledge was significantly higher in the upper and middle SES levels than it was in the lower SES level $(P<0.001)$. More than half of the patients (68\%) were not aware of the existing FP options, whereas one-third of the patients $(32 \%)$ were given information about FP by their physicians.

\section{Conclusion}

The overall awareness of the gonadotoxic effect of cancer therapy and available FP options in the present study was poor. Awareness of FP among both patients and clinicians needs to be increased.

Keywords: Cancer; Fertility preservation; Knowledge; Awareness; Chemotherapy

\section{Introduction}

The global cancer burden is estimated to have increased to 18.1 million new cases and 9.6 million deaths in 2018 [1]. One in 5 men and 1 in 6 women worldwide develop cancer during their lifetime and 1 in 8 men and 1 in 11 women die from the disease [1]. With the advances in cancer treatment, including surgery, chemotherapy, and radiotherapy, the overall survival rate of patients with cancer has improved, especially in the last 2-3 decades. Survival rates are the highest in patients with cancer in the 15-44-year age group,
Received: 2019.12.27. Revised: 2020.04.22. Accepted: 2020.05.05. Corresponding author: Neena Malhotra, MD, DNB, FRCOG Department of Obstetrics \& Gynecology, All India Institute of Medical Sciences, Ansari Nagar-10029, New Delhi, India E-mail: malhotraneena@yahoo.com https://orcid.org/0000-0001-7837-5361

Articles published in Obstet Gynecol Sci are open-access, distributed under the terms of the Creative Commons Attribution Non-Commercial License (http://creativecommons. org/licenses/by-nc/3.0/) which permits unrestricted non-commercial use, distribution, and reproduction in any medium, provided the original work is properly cited.

Copyright $\odot 2020$ Korean Society of Obstetrics and Gynecology 


\section{Obstetrics \& Gynecology Science}

Reeta Mahey, et al. Oncofertility awareness among females

with a 5-year survival rate ranging between $60 \%$ and $82 \%$ [2-5]. However, cancer treatment has many undesirable side effects, including impaired fertility, which occurs in approximately $80 \%$ of survivors and becomes an important qualityof-life issue in these patients $[6,7]$. Cancer itself affects fertility when it involves reproductive organs that need to be surgically removed, and when treatment involves gonadotoxic chemotherapy or radiotherapy in the pelvic field or the hypothalamus-pituitary area of the brain. Because of late marriages and delayed childbearing, the proportion of young patients with cancer who have yet to plan for their first pregnancy is increasing. Sometimes the only fertility option left for these cancer survivors is the use of donated gametes.

Oncofertility, a term coined by Woodruff in 2006, combines cancer treatment with fertility preservation (FP) for young women with cancer who desire future fertility [8]. Various FP methods have evolved over the last 2 decades. Among them, embryo and oocyte cryopreservation are established methods of fertility preservation with possibility of having own genetic offspring in future. Translocation of the ovaries to above the pelvic brim protects the ovaries from pelvic radiotherapy. However, translocation is not always successful because of radiation scatter and remigration of the ovaries and is of no benefit when treatment involves chemotherapy or whole-body irradiation. Ovarian tissue cryopreservation is still in the experimental stage and suppression of the ovaries with gonadotropin-releasing hormone agonist $(\mathrm{GnRHa})$ has limited benefit for FP [9-11].
The American Society of Clinical Oncology (ASCO) and the American Society of Reproductive Medicine (ASRM) recommend that all possible FP options should be discussed with women diagnosed with cancer before starting any gonadotoxic therapy [12].

Despite the recommendations of international societies, more than half of patients with cancer are not given all the information they need about FP options and very few patients actually undergo any FP procedure [13-16]. The primary reason behind these facts might be a lack of awareness among patients and treating physicians regarding possible FP strategies [17]. In addition, sociodemographic disparities have been shown to affect access to FP services $[18,19]$. These disparities may be due to disparities in education status and the inability to afford FP. Other reasons why few patients undergo an FP procedure include time constraints, fear about the safety of the procedure, fear of the risk of cancer recurrence from a future pregnancy, and fear of the transmission of cancer to offspring.

The present observational study was conducted to evaluate the knowledge and awareness of female patients with cancer attending the OBGYN outpatient clinic and the infertility clinic at our institute regarding the effect of cancer treatment on future fertility and available methods of FP. We also categorized the participants according to their socioeconomic status (SES) using the recent classification system applicable to the Indian population and assessed the difference in knowledge among the SES groups.

\begin{tabular}{|c|c|c|c|c|c|}
\hline Education of head of family & Score & Occupation of head of family & Score & Monthly income of family (Jan 2017) & Score \\
\hline Profession or honours & 7 & Profession & 10 & $>41430$ & 12 \\
\hline Graduate or post graduate & 6 & Semi- professional & 6 & 20715-41429 & 10 \\
\hline $\begin{array}{l}\text { Intermediate or post high school } \\
\text { diploma }\end{array}$ & 5 & Clerical, Shop-owner & 5 & $15536-20714$ & 6 \\
\hline High school certificate & 4 & Skilled worker & 4 & $10357-15535$ & 4 \\
\hline Middle school certificate & 3 & Semi-skilled worker & 3 & $6214-10356$ & 3 \\
\hline Primary school certificate & 2 & Unskilled worker & 2 & $2092-6213$ & 2 \\
\hline Illiterate & 1 & Unemployed & 1 & $<2091$ & 1 \\
\hline Socioeconomic class & & & & \multicolumn{2}{|l|}{ Total Score } \\
\hline 1 & \multicolumn{3}{|l|}{ Upper } & \multicolumn{2}{|l|}{$26-29$} \\
\hline ॥ & \multicolumn{3}{|c|}{ Upper middle } & \multicolumn{2}{|l|}{$16-25$} \\
\hline III & \multicolumn{3}{|c|}{ Lower middle } & \multicolumn{2}{|l|}{$11-15$} \\
\hline IV & \multicolumn{3}{|c|}{ Upper lower } & \multicolumn{2}{|l|}{$5-10$} \\
\hline v & \multicolumn{3}{|l|}{ Lower } & \multicolumn{2}{|l|}{$<5$} \\
\hline
\end{tabular}

Fig. 1. Modified Kuppuswamy socioeconomic status scale. 


\section{Obstetrics \& Gynecology Science}

Vol. 63, No. 4, 2020

\section{Materials and methods}

This was a cross-sectional study conducted at a tertiary care referral center from March 2019 through August 2019. Ethical approval was obtained from the Ethics Committee of the All India Institute of Medical Sciences (Ref. No. IEC9/04.01.2019, RP-50/2019) and informed consent was obtained from all the participants. Inclusion criteria were age from 18-40 years old, diagnosis of cancer, and attendance at the infertility clinic. The women who visited the infertility clinic were referred either by the OBGYN clinic (gynecological cancer) or by other specialties for FP. A total of 100 women participated in the study. Participation was completely voluntary, and a fertility counselor interviewed each participant. The questionnaire (Appendix 1) elicited information about the sociodemographic profile of the participants and contained questions to determine knowledge regarding the effect of cancer treatment on future fertility and the gonadotoxic effect of chemotherapy and radiotherapy, awareness of $\mathrm{FP}$, whether information regarding the effect of cancer on fertility and FP was provided by the primary physician, and the reasons for not proceeding with FP. The study population was stratified into 5 SES categories according to the modified Kuppuswamy scale (Fig. 1) [20]. Because the number of patients in each group was small, the upper-middle and lower-middle SES categories were combined into a single middle SES category and the upper-lower and lower SES categories were combined into a single lower SES category. The knowledge levels of the three SES groups (upper, middle, and lower) were compared.

\section{Statistical analysis}

All statistical analyses were performed using IBM SPSS Statistics version 19 (IBM Corp., Armonk, NY, USA). Descriptive statistics were used for quantitative variables and are expressed as mean, standard deviation (SD) or frequency, and percentage. The responses of participants was stratified according to the SES scale. To compare the categorical data, Pearson's chi-square test or a Fisher exact test was performed as appropriate. A post hoc pairwise comparison was also performed using Bonferroni's correction. For all statistical tests, $P<0.05$ was considered to be statistically significant.

\section{Results}

A total of 100 women participated in the study. The sociodemographic characteristics of the study population are presented in Table 1 . The mean $( \pm S D)$ age of the study cohort was $28.8 \pm 7.36$ years. Forty-eight percent $(48 \%)$ of the patients came from the OBGYN clinic and $52 \%$ were referred by other departments in our hospital or by other hospitals.

Table 1. Baseline demographic profile of the study subjects $(n=100)$

\begin{tabular}{|c|c|}
\hline Characteristics & Values \\
\hline \multicolumn{2}{|l|}{ Age (yr) } \\
\hline$<20$ & $16(16)$ \\
\hline $20-35$ & $63(63)$ \\
\hline$>35$ & $21(21)$ \\
\hline \multicolumn{2}{|l|}{ Type of family } \\
\hline Nuclear & $56(56)$ \\
\hline Joint & $44(44)$ \\
\hline \multicolumn{2}{|l|}{ Marital status } \\
\hline Married & $71(71)$ \\
\hline Single & $29(29)$ \\
\hline \multicolumn{2}{|l|}{ Education } \\
\hline Illiterate & $19(19)$ \\
\hline Primary & $10(10)$ \\
\hline Secondary & $26(26)$ \\
\hline Graduate and above & $45(45)$ \\
\hline \multicolumn{2}{|l|}{ Socioeconomic status } \\
\hline Lower & $51(51)$ \\
\hline Middle & $44(44)$ \\
\hline Upper & $5(5)$ \\
\hline \multicolumn{2}{|c|}{ Fertility at the time of diagnosis } \\
\hline Living child & $43(43)$ \\
\hline No living child & $28(28)$ \\
\hline Unmarried & $29(29)$ \\
\hline \multicolumn{2}{|l|}{ Type of cancer } \\
\hline Ca ovary & $30(30)$ \\
\hline Ca breast & $25(25)$ \\
\hline Ca cervix & $11(11)$ \\
\hline Lymphoma & $17(17)$ \\
\hline Ca endometrium & $7(7)$ \\
\hline Others & $10(10)$ \\
\hline
\end{tabular}

Values are presented as number (\%). 


\section{Obstetrics \& Gynecology Science}

Reeta Mahey, et al. Oncofertility awareness among females

Seventy-one percent $(71 \%)$ of the participants were married at the time of the cancer diagnosis and $29 \%$ were unmarried. When asked about the desire for bearing a child in the future, 57 patients (28 of whom were married) indicated they wanted children in the future, 6 patients had not yet decided, and the remaining 37 patients had at least one living child and were not interested in FP. Comparing the wish for future fertility among the SES classes, significantly more women in the upper SES class than in the lower SES class wished to have future fertility. This may be due to the increasing trend of delayed childbearing by the upper SES class (60\% vs. $11.8 \%)(P=0.017)$.

When asked about their knowledge of the effect of cancer and its treatment on future fertility, only $32 \%$ of the women were aware that cancer treatment might impair future fertility. When specifically asked about the gonadotoxic effect of chemotherapy and radiotherapy, only $28 \%$ of the women had an awareness of the effect. As shown in Fig. 2A, significantly more women in the upper SES class were aware of the harmful effect of cancer therapy on future fertility and of the gonadotoxic effect of chemotherapy and radiotherapy. The pairwise comparison with Bonferroni correction showed that there was a significant difference in awareness of the harmful effect of cancer therapy between the upper and lower SES classes $(P=0.003)$ and between the middle and lower SES classes $(P=0.001)$. Similarly, with respect to awareness of the gonadotoxic effect, there was significant difference between the upper and lower SES classes $(P=0.017)$ and between the middle and lower SES classes $(P=0.001)$. However, there was no significant difference ( $P>0.05)$ between the upper and middle groups for the two parameters. Less than one-third (32\%) of the women were aware of FP, and of them, $28 \%$ were aware of oocyte and embryo cryopreservation. This awareness was significantly higher in the upper and middle SES classes (Fig. 2A). We found that none of the patients in the lower education groups (illiterate and primary education) had knowledge regarding the effect of cancer and gonadotoxic effect of chemotherapy on fertility, whereas significantly more women in the higher education group (graduate and above) had more knowledge in this regard (Fig. 2B). Also, awareness of FP was significantly greater in the higher education group (Fig. 2B). More than half of the women (68\%) were not given any information by their primary physician regarding the effect of cancer treatment on future fertility and about FP. Patients who desired future fertility cited lack of information, financial constraints, lack of family support, and fear of delay in cancer treatment as reasons for not pursuing treatment. The most common reason among $28.6 \%$ of the patients was lack of proper information from their physicians. Only 11 patients underwent the FP procedure and 5 patients had to undergo surgical removal of the uterus and ovaries because of cancer. Follow-up found that 2 patients who underwent FP died.

\section{Discussion}

The present cross-sectional study evaluated the knowledge and awareness of female patients with cancer regarding the gonadotoxic effect of cancer therapy and FP options.
A

Percent awareness according to SES

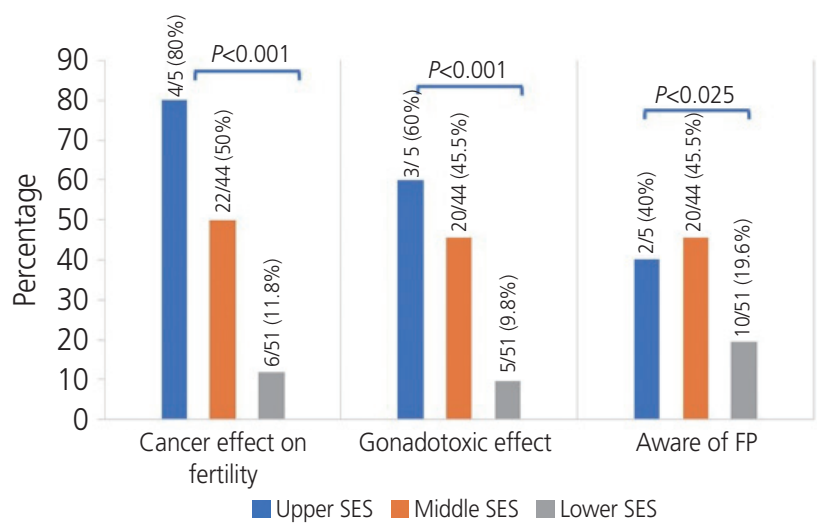

B

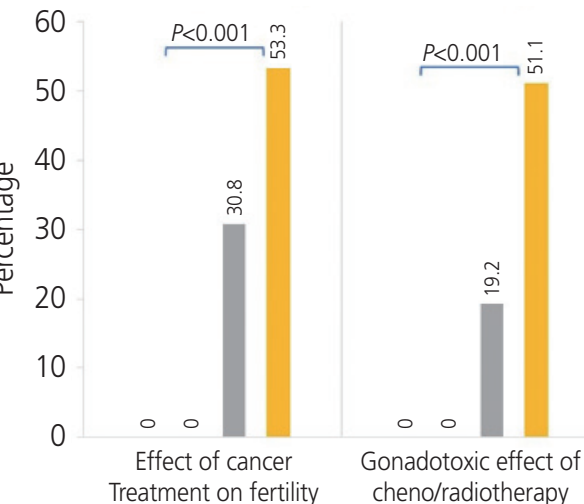

Awareness according to education

- Illiterate $\square$ Primary $\square$ Secondary $\square$ Graduate and above

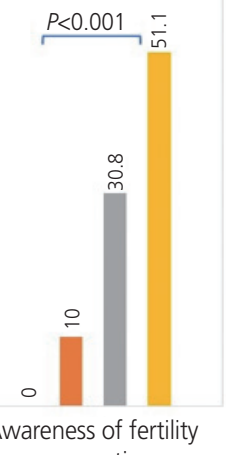
preservation

Fig. 2. Oncofertility awareness according to (A) SES and (B) education of the patient. SES, socioeconomic status. 


\section{Obstetrics \& Gynecology Science}

Vol. 63, No. 4, 2020

The study was conducted at the infertility clinic of a tertiary care referral government institute so most of the women belonged the to lower and middle SES levels. The study concluded that overall knowledge and awareness about the harmful effect of cancer therapies and about FP before initiating gonadotoxic treatment was poor. Women in the lower SES class had significantly less knowledge than did women in the upper SES class. Similarly, knowledge was significantly low in the lower literacy groups.

About $10 \%$ of cancer patients are $<45$ years of age at the time of diagnosis [21]. Advances in cancer therapy have led to a remarkable improvement in the survival rates of patients with cancer. The overall cancer death rates have fallen by more than 1.6\% per year between 2004 and 2008 [22]. Because of the trend of delayed childbearing, more women are diagnosed with cancer before they have planned their first pregnancy. This has led to the need for FP for which various options are available in accordance with the age of the patient, the type of cancer and prognosis, the type and dose of chemotherapy, marital status, and existing ovarian reserve.

Both radiotherapy and chemotherapy can impair fertility. Chemotherapy affects fertility via gonadotoxicity, and radiotherapy, if it involves the pelvis, affects the reproductive organs (ovary and uterus) [23]. Studies have shown that the rate of fertility and pregnancy of patients after cancer treatment is 38\% lower than that of women in the general population [24].

Considering the improved survival rates among young patients with cancer and impaired fertility after cancer treatment, it is important to counsel these patients about the harmful effects of cancer treatment on future fertility and the available FP options. Lack of knowledge about FP among physicians and patients can lead to financial, legal, and psychological consequences.

The most common nongynecological cancers in our patient cohort were breast cancer and lymphomas. One of the main treatment modalities for these cancers is chemotherapy with alkylating agents, which are highly gonadotoxic because they are not cell cycle specific and affect other cells in the ovaries. If these cancers are detected at an early stage, patients have good overall survival, and with FP, they have a better chance of achieving pregnancy in the future. In our study, the awareness of FP did not differ much among patients with different types of cancer because overall knowledge was poor, but patients with breast cancer or lymphoma who have a good prognosis will benefit greatly from FP.

Our study found that approximately two-thirds of the patients were not aware of the effect of cancer treatment on fertility and of the gonadotoxic effect of chemotherapy and radiotherapy. A study conducted in Pakistan demonstrated a lack of awareness in more than $90 \%$ of young female patients with cancer about cancer treatment causing infertility [25]. Other studies have also demonstrated poor knowledge of the effect of cancer treatment on fertility $[26,27]$.

Because knowledge about oncofertility among patients and physicians is poor, patients do not get the right information about the methods available to preserve their fertility and about the possibility of having their own genetic children in the future once cancer treatment is completed. In a study by Chin et al. [28], only $60 \%$ of women with cancer received fertility counseling before starting cancer therapy and only $13 \%$ of those women were referred to a fertility specialist. Our study showed comparable results whereby $68 \%$ of the study population was not counseled by their primary physician about the gonadotoxic effect of cancer therapy on future fertility.

This lack of knowledge about the harmful effect of cancer therapy may be due to low SES and low education level. The Chin et al. [28] study showed that women who had less education, were unmarried, or already had a child were less likely to receive fertility counseling because fertility is not considered a primary concern for these women. Our study also showed that women of low SES and those with a low education level had significantly less knowledge about the harmful effect of cancer therapy compared to that of their respective counterparts.

ASCO and ASRM guidelines recommend that patients with cancer should be given sufficient information about cancer treatment-related infertility and available fertility options [29]. However, studies have shown that physicians and patients have insufficient knowledge about FP [30,31]. Chehin et al. [32] assessed patients with cancer for their knowledge and awareness about FP and found that only $34 \%$ of the women were aware that cancer therapy could lead to infertility and only $22 \%$ were aware of FP options. Higher education was associated with more knowledge about the effect of cancer therapy on fertility and available FP options. Chehin et al. [32] concluded that patients with cancer had poor overall knowledge about FP. We found similar results in our study with only one-third of the women aware of the gonadotoxic 


\section{Obstetrics \& Gynecology Science}

Reeta Mahey, et al. Oncofertility awareness among females

effect of cancer treatment and less than one-third (28\%) having knowledge about FP. In addition, those with a higher education had better knowledge.

More than $90 \%$ of the patients in a study by Osmani et al. [25] wanted to discuss fertility issues with their primary oncologist before initiation of treatment, but other studies have found that less than half of the participants were offered a detailed consultation $[21,17]$. In our study, only $32 \%$ of the patients were informed about FP by their primary physician. Similarly, Ameri et al. [33] found that only $22.7 \%$ of their study patients received information regarding cancer treatment and infertility. However, they also found that significantly more patients with gynecological cancer received information compared to those with nongynecological cancer [33]. In contrast, studies conducted in the US and Switzerland found that more than $70 \%$ of the participants were informed by their healthcare professionals about fertility impairment after cancer treatment $[31,34]$. This regional difference in physician counseling may be due to a greater adherence to guidelines in countries like US and Switzerland in comparison to India, Brazil and Iran [32,33]. Reports have shown that only British and American physicians discuss fertility issues with their patients $[30,35]$.

Some studies have shown that disparities in providing information depended on the gender of the patient $[34,36]$. In a study by Armuand et al. [36], only $48 \%$ of the women compared to $80 \%$ of the men received information about the risk of infertility with cancer treatment. The reasons behind this difference might be that cryopreservation of sperm is a relatively simple procedure and less costly compared to female FP methods, and for men there is no delay in starting cancer treatment. Female FP methods have many barriers including the time needed for hormonal medication to stimulate the ovaries, delayed cancer treatment, financial constraints, and the fear of risks associated with ovarian stimulation. To overcome these barriers, the oncologist and the reproductive endocrinologist could collaborate to prevent delay in referral, financial support arranged from government and nongovernment organization to cover expenses for $\mathrm{FP}$, and ovarian stimulation protocols could be modified for minimal risk and overall less time required to complete the procedure.

Kim et al. [37] conducted a prospective study to evaluate the efficacy of the FP consultation process and predictors of decisional conflict among patients in need of FP. More than half $(52 \%)$ of the participants requested their consultation, all participants answered that consultation was a helpful resource for information, and $73 \%$ of the participants made their decision about treatment after consultation. The consultation helped the patients formulate questions related to FP. Although consultation appeared to play a critical role in the decision-making of the patients about FP, the referral rate for consultation by oncologists was still poor [37].

Various reasons for not opting for FP may be the cost, a lack of proper information among both patients and treating physicians, fear of delaying cancer treatment and fear of risk of transmission of cancer to future offspring among patients with cancer.

To increase the knowledge of oncologists about FP, a Cancer and Fertility Platform was established in 2012 to provide a website with up-to-date information, communication tools, and ready-to-use script for fertility counseling [26]. After 3 years of use of the Cancer and Fertility Platform, the knowledge and practices of physicians were evaluated. The survey showed that referrals for FP by the cancer physicians was significantly higher after using the Cancer and Fertility Platform [38]. According to a recent systematic review of factors to improve oncofertility care, referrals for FP are very low worldwide, even after the publication of international guidelines on FP. International oncofertility models of care (MOC) are needed to train cancer and noncancer healthcare professionals to improve their knowledge about FP so they can convey that knowledge to patients requiring a referral [39]. A multidisciplinary team that includes an oncologist, a fertility specialist, a nurse counsellor, and a mental health professional is needed to provide high-quality cancer care to these patients.

One limitation of our study was its small sample size as a result of few patients being referred to us for FP. We assessed the knowledge of only female patients with cancer and not that of physicians. Another limitation was that the participants were patients with cancer who were consulting at a tertiary referral center. Knowledge and awareness of FP are expected to be poor among the general population. To our knowledge, this was the first study of Indian female patients with cancer.

Our study showed that the overall knowledge of young female patients with cancer regarding fertility impairment following cancer treatment and available FP options is poor. Because life expectancy after cancer treatment is increasing, 


\section{Obstetrics \& Gynecology Science}

Vol. 63, No. 4, 2020

the option of FP should be a topic of interest among all oncologists. It is important to provide standardized up-to-date information and systematically offer oncofertility counseling to patients of reproductive age who are scheduled for cancer treatment. This can be accomplished by adopting a structured program that includes having a detailed face-toface discussion with patients, providing them with written information about the various aspects of oncofertility, and organizing education programs for patients and concerned physicians.

\section{Acknowledgements}

We thank the study participants for their patience during the interview and the oncology residents for referring patients to us.

\section{Conflict of interest}

No potential conflict of interest relevant to this article was reported.

\section{Ethical approval}

Ethical approval was obtained from the Ethics Committee of the All India Institute of Medical Sciences (Ref. No. IEC9/04.01.2019, RP-50/2019).

\section{Patient consent}

Informed consent was obtained from all the participants.

\section{References}

1. Ferlay J, Colombet M, Soerjomataram I, Mathers C, Parkin DM, Piñeros $M$, et al. Estimating the global cancer incidence and mortality in 2018: GLOBOCAN sources and methods. Int J Cancer 2019;144:1941-53.

2. van Dijk $M$, van den Berg $M H$, Overbeek $A$, Lambalk $C B$, van den Heuvel-Eibrink MM, Tissing WJ, et al. Reproductive intentions and use of reproductive health care among female survivors of childhood cancer. Hum Reprod 2018;33:1167-74.

3. Ward E, DeSantis C, Robbins A, Kohler B, Jemal A. Childhood and adolescent cancer statistics, 2014. CA Cancer J Clin 2014;64:83-103.

4. Coleman MP, Quaresma M, Berrino F, Lutz JM, De Angelis $R$, Capocaccia $R$, et al. Cancer survival in five continents: a worldwide population-based study (CONCORD). Lancet Oncol 2008;9:730-56.

5. Haggar FA, Pereira G, Preen DD, Holman CD, Einarsdottir K. Cancer survival and excess mortality estimates among adolescents and young adults in Western Australia, 1982-2004: a population-based study. PLoS One 2013;8:e55630.

6. Campo-Engelstein L. Consistency in insurance coverage for iatrogenic conditions resulting from cancer treatment including fertility preservation. J Clin Oncol 2010;28:1284-6.

7. Peate $M$, Meiser B, Hickey M, Friedlander M. The fertility-related concerns, needs and preferences of younger women with breast cancer: a systematic review. Breast Cancer Res Treat 2009;116:215-23.

8. Woodruff TK. The Oncofertility Consortium--addressing fertility in young people with cancer. Nat Rev Clin Oncol 2010;7:466-75.

9. Irene Su H, Lee YT, Barr R. Oncofertility: meeting the fertility goals of adolescents and young adults with cancer. Cancer J 2018;24:328-35.

10. Loren AW, Mangu PB, Beck LN, Brennan L, Magdalinski AJ, Partridge $A H$, et al. Fertility preservation for patients with cancer: American Society of Clinical Oncology clinical practice guideline update. J Clin Oncol 2013;31:2500-10.

11. Oktay K, Harvey BE, Partridge AH, Quinn GP, Reinecke J, Taylor HS, et al. Fertility preservation in patients with cancer: ASCO clinical practice guideline update. J Clin Oncol 2018;36:1994-2001.

12. Ethics Committee of the American Society for Reproductive Medicine. Fertility preservation and reproduction in cancer patients. Fertil Steril 2005;83:1622-8.

13. Corney RH, Swinglehurst AJ. Young childless women with breast cancer in the UK: a qualitative study of their fertility-related experiences, options, and the information given by health professionals. Psychooncology 2014;23:20-6. 


\section{Obstetrics \& Gynecology Science}

Reeta Mahey, et al. Oncofertility awareness among females

14. Geue K, Richter D, Schmidt R, Sender A, Siedentopf F, Brähler $E$, et al. The desire for children and fertility issues among young German cancer survivors. J Adolesc Health 2014;54:527-35.

15. Yee S, Abrol K, McDonald M, Tonelli M, Liu KE. Addressing oncofertility needs: views of female cancer patients in fertility preservation. J Psychosoc Oncol 2012;30:33146.

16. Niemasik EE, Letourneau J, Dohan D, Katz A, Melisko M, Rugo $\mathrm{H}$, et al. Patient perceptions of reproductive health counseling at the time of cancer diagnosis: a qualitative study of female California cancer survivors. J Cancer Surviv 2012;6:324-32.

17. Sallem A, Shore J, Ray-Coquard I, Ferreux L, Bourdon $\mathrm{M}$, Maignien $\mathrm{C}$, et al. Fertility preservation in women with cancer: a national study about French oncologists awareness, experience, and feelings. J Assist Reprod Genet 2018;35:1843-50.

18. Letourneau JM, Smith JF, Ebbel EE, Craig A, Katz PP, Cedars $\mathrm{Ml}$, et al. Racial, socioeconomic, and demographic disparities in access to fertility preservation in young women diagnosed with cancer. Cancer 2012;118:457988.

19. Goodman LR, Balthazar U, Kim J, Mersereau JE. Trends of socioeconomic disparities in referral patterns for fertility preservation consultation. Hum Reprod 2012;27:2076-81.

20. Singh T, Sharma S, Nagesh S. Socio-economic status scales updated for 2017. Int J Res Med Sci 2017;5:32647.

21. Howlader N, Noone A, Krapcho M, Miller D, Brest A, Yu M, et al. SEER cancer statistics review, 1975-2016. Bethesda (MD): National Cancer Institute; 2020 [cited 2019 Apr 7]. Available from: https://seer.cancer.gov/ csr/1975_2016.

22. Siegel $R$, Naishadham $D$, Jemal $A$. Cancer statistics, 2012. CA Cancer J Clin 2012;62:10-29.

23. Biedka M, Kuźba-Kryszak T, Nowikiewicz T, Żyromska A. Fertility impairment in radiotherapy. Contemp Oncol (Pozn) 2016;20:199-204.

24. Stensheim H, Cvancarova M, Møller B, Fosså SD. Pregnancy after adolescent and adult cancer: a population-based matched cohort study. Int J Cancer 2011;129:1225-36.

25. Osmani AH, Haider G, Ali S, Ali F, Irfan M, Fatima DE.
Knowledge and perceptions about cancer treatmentassociated infertility among young patients at a tertiary care hospital in Pakistan. Asian Pac J Cancer Prev 2017;18:3261-5.

26. Kim J, Mersereau JE. A pilot study about female adolescent/young childhood cancer survivors' knowledge about reproductive health and their views about consultation with a fertility specialist. Palliat Support Care 2015;13:1251-60.

27. Duffy CM, Allen SM, Clark MA. Discussions regarding reproductive health for young women with breast cancer undergoing chemotherapy. J Clin Oncol 2005;23:76673.

28. Chin HB, Howards PP, Kramer MR, Mertens AC, Spencer $J B$. Which female cancer patients fail to receive fertility counseling before treatment in the state of Georgia? Fertil Steril 2016;106:1763-1771.e1.

29. Peccatori FA, Azim HA Jr, Orecchia R, Hoekstra HJ, Pavlidis $N$, Kesic $V$, et al. Cancer, pregnancy and fertility: ESMO Clinical Practice Guidelines for diagnosis, treatment and follow-up. Ann Oncol 2013;24 Suppl 6:vi16070.

30. Adams $E$, Hill E, Watson E. Fertility preservation in cancer survivors: a national survey of oncologists' current knowledge, practice and attitudes. Br J Cancer 2013;108:1602-15.

31. Urech C, Ehrbar V, Boivin J, Müller M, Alder J, Zanetti Dällenbach $\mathrm{R}$, et al. Knowledge about and attitude towards fertility preservation in young female cancer patients: a cross-sectional online survey. Hum Fertil (Camb) 2018;21:45-51.

32. Chehin MB, Bonetti TC, Serafini PC, Motta E. Knowledge regarding fertility preservation in cancer patients: a population-based survey among Brazilian people during the Pink October awareness event. JBRA Assist Reprod 2017;21:84-8.

33. Ameri A, Novin K, Sourati A, Rashidi P. Awareness of female cancer patients about the risk of impaired fertility. J Adolesc Young Adult Oncol 2019;8:342-8.

34. Shnorhavorian M, Harlan LC, Smith AW, Keegan TH, Lynch CF, Prasad PK, et al. Fertility preservation knowledge, counseling, and actions among adolescent and young adult patients with cancer: a population-based study. Cancer 2015;121:3499-506.

35. Forman EJ, Anders CK, Behera MA. A nationwide sur- 


\section{Obstetrics \& Gynecology Science}

Vol. 63, No. 4, 2020

vey of oncologists regarding treatment-related infertility and fertility preservation in female cancer patients. Fertil Steril 2010;94:1652-6.

36. Armuand GM, Rodriguez-Wallberg KA, Wettergren $L$, Ahlgren J, Enblad G, Höglund M, et al. Sex differences in fertility-related information received by young adult cancer survivors. J Clin Oncol 2012;30:2147-53.

37. Kim J, Deal AM, Balthazar U, Kondapalli LA, Gracia C, Mersereau JE. Fertility preservation consultation for women with cancer: are we helping patients make highquality decisions? Reprod Biomed Online 2013;27:96103.
38. Réseau Régional de Cancérologie OncoPaca-Corse. La Plateforme Régionale Cancer \& Fertilité [Internet]. Marseille: Réseau Régional de Cancérologie OncoPacaCorse; 2020 [cited 2019 Apr 7]. Available from: http:// www.oncopaca.org/fr/page/la-plateforme-regionalecancer-fertilite-oncofertilite.

39. Anazodo A, Laws P, Logan S, Saunders C, Travaglia J, Gerstl B, et al. How can we improve oncofertility care for patients? A systematic scoping review of current international practice and models of care. Hum Reprod Update 2019;25:159-79. 


\section{Obstetrics \& Gynecology Science}

Reeta Mahey, et al. Oncofertility awareness among females

Appendix 1. Questionnaire

Name

Age

UHID No.

Phone number:

Family size

Referred from

Marital status at the time of diagnosis: married/unmarried

Type of cancer:

Fertility status at the time of diagnosis (No. of abortions/living children):

Education: Income:

Profession: $\quad$ Socioeconomic status:

Q1. What was your age at the time of your cancer diagnosis?

Q2. Do you intend to have more children? Yes/no/not yet decided

Q3. Do you have any idea that cancer will affect your future fertility? Yes/no

Q4. Of these, what type of treatment have you received/are planning to receive for cancer?
a. Surgery
b. Chemotherapy
c. Radiotherapy
d. Combination

Q5. Are you aware of the gonadotoxic effect of chemotherapy/radiotherapy on future fertility and ovarian function? Yes/no/ don't know

Q6. Were you given proper FP options information before going for gonadotoxic treatment? Yes/no/don't know

Q7. What is/was the reason for not opting for FP before treatment?

\begin{tabular}{lccc}
\hline Did not have information & Financial reason & Lack of family support & Was not informed by physician \\
\hline $\begin{array}{l}\text { Did not want to delay my } \\
\text { cancer treatment }\end{array}$ & $\begin{array}{c}\text { Risk of transmission of } \\
\text { cancer to the future child }\end{array}$ & $\begin{array}{c}\text { Already had desired children } \\
\text { at that time }\end{array}$ & Any other \\
\hline
\end{tabular}

Q8. Are you aware of available FP options for you? Yes/no

\begin{tabular}{lcc}
\hline Oocyte cryopreservation & Embryo cryopreservation & Ovarian cortex preservation \\
\hline Shield from radiation field & GnRHa suppression & Ovarian transposition \\
\hline
\end{tabular}

